NBER WORKING PAPER SERIES

\title{
EVALUATING TRADE REFORM USING EX-POST CRITERIA
}

\author{
Jiandong Ju \\ Kala Krishna
}

Working Paper 6152

http://www.nber.org/papers/w6152

\author{
NATIONAL BUREAU OF ECONOMIC RESEARCH \\ 1050 Massachusetts Avenue \\ Cambridge, MA 02138 \\ September 1997
}

This work has been supported by grant SBR-9320825 from the National Science Foundation to the National Bureau of Economic Research. This paper is part of NBER's research program in International Trade and Investment. Any opinions expressed are those of the authors and not those of the National Bureau of Economic Research.

(C) 1997 by Jiandong Ju and Kala Krishna. All rights reserved. Short sections of text, not to exceed two paragraphs, may be quoted without explicit permission provided that full credit, including (C) notice, is given to the source. 
Evaluating Trade Reform Using

Ex-Post Criteria

Jiandong Ju and Kala Krishna

NBER Working Paper No. 6152

September 1997

JEL Nos. F0, F1

International Trade and Investment

\begin{abstract}
In contrast to existing work which takes an ex-ante approach and looks for policy prescriptions which yield welfare improvements, we take an ex-post approach. We ask whether there are indicators which show whether welfare has risen or not in the wake of a reform. That is, we look for evidence of welfare improvements in outcome space. Necessary and sufficient conditions for welfare improving trade reform are derived. These conditions are shown to be useful in evaluating Free Trade Areas and in reforming Article XXIV of GATT.
\end{abstract}

Jiandong Ju

Department of Economics

729 Elm Avenue, Room 329 Hester Hall

University of Oklahoma

Norman, OK 73019
Kala Krishna

Department of Economics

401 Kern Graduate Building

The Pennsylvania State University

University Park, PA 16802

and NBER

kmk4@psuvm.psu.edu 


\section{Introduction}

What kinds of reforms are welfare enhancing? Are there unilateral reforms which cause Pareto improvements? What about multilateral ones? These questions lie at the heart of policy debates. In economics, such questions have been dealt with in the area of piecemeal policy reform. It is well understood from the theory of the second best that in the presence of existing distortions, movement towards the first best need not be welfare enhancing. Nevertheless, two basic results exist. The first shows that uniform proportional cuts $(U P C)$ in tariffs raise welfare. The second shows that reduction of the highest ad-valorem tariff to the next highest one raises welfare if all goods are net substitutes. This is termed the concertina rule. Recently, Lopez and Panagariya (1990) argue that the net substitutes assumption is not plausible in the presence of pure imported intermediate goods. ${ }^{1}$ As a large part of trade, especially for developing countries is in intermediate goods, the applicability of the concertina rule is limited by their finding. ${ }^{2}$

\footnotetext{
${ }^{\mathrm{I}}$ Essentially they argue that a tariff on a pure intermediate good acts like a supply shock. It acts like a reduction in the availability of a factor of production. Then, by the Rybczynski Theorem, the output of one final good must fall and the other rise. Thus, for at least one final good, an increase in the price of the intermediate good must reduce the excess demand for the final good, that is, the goods are complements.

${ }^{2}$ While there is a huge literature in the area, some recent papers are particularly noteworthy. Anderson and Neary (1992a) (1990) get some interesting results on peicemeal policy reform and derive a distance function based index of trade reform by assuming that the trade expenditure function (the difference between the expenditure and revenue functions) satisfies an implicit separability condition. They allow for partial rent retention, tariffs, as well as quotas in their
} 
Most of the work in the area takes what we term an ex-ante approach. It looks for policy prescriptions which will yield welfare improvements. In other words, it looks for regions in policy space where welfare rises. In contrast, we take what we call an ex-post approach. We ask: are there indicators which can be examined in order to see if welfare has risen or not due to a reform? Our work is based on the work of Ohyama (1972). Ohyama looks for sufficient conditions for a welfare improvement. In Section 3 we summarize his results. While Ohyama's results are couched in terms of a representative consumer, we show in an Appendix that in the small country case they also hold with many consumers and lump sum or non lump sum taxes and transfers being allowed. We first apply Ohyama's conditions to evaluating Free Trade Areas (FTAs). Following this, we look at the necessary conditions for a welfare improvement and apply them to evaluating FTAs. We then look at the effect of reform in one country on the welfare of other countries. We derive a condition under which some country or countries must lose as a result of the reform. Such results are likely to be useful in reforming Article $X X I V$ of GATT which places some constraints on the formation of Customs Unions.

formulation. However, implicit separability of the trade expenditure function is a very strong assumption and this limits the generality of their results. In contrast to all of the above, which deal with unilateral reform, Turunen-Red and Woodland (1990), (1991) deal with multilateral reform. They look for Pareto improving reforms of tariffs and taxes when international transfers are allowed. Their approach uses Motzkin's theorem of the alternative rather than the standard comparative static approach. However, in contrast to the minimal information requirement of the concertina and UPC rules, these rules require a good deal of information in order to be implemented. 
While our results do not help guide policy ex-ante, they may help in providing guidelines which need to be met. A major question in the policy arena has been about which Preferential Trading Agreements or PTAs should be permitted and which should not. In the next section, we provide a quick survey of the major ideas and problems in this area and argue that an ex-post criterion might be useful here.

\section{Welfare-enhancing FTAs}

There has been considerable and growing interest in Preferential Trading Agreements $(P T A s)$ in recent years. Between the initiation of the Uruguay Round in 1976 and the creation of the WTO on January 1, 1995, there was notification given to GATT of as many as 44 such agreements! Since then, at least another 12 have been added! It is worth comparing these figures to those for the previous three decades when 54 notifications were given. ${ }^{3}$

However, it is far from clear whether such agreements should be encouraged or not. If one asks what some indicators of welfare-enhancing preferential trading agreements might be, a fair amount of confusion becomes apparent. On the one hand, non discrimination is seen as a cornerstone of GATT and the WTO, yet PTAs despite being fundamentally discriminatory are allowed.

\footnotetext{
${ }^{3}$ These figures come from Srinivasan (1996).
} 
Article XXIV on the creation of customs unions does put some constraints on their creation. In particular, it requires that:

"(i)...the duties and other regulations of commerce...shall not on the whole be higher or more restrictive than the general incidence of the duties or regulations...prior to the formation of such union or the adoption of such interim agreement.

(ii) Duties ... are eliminated with respect to substantially all trade between constituent territories of the union or at least with respect to substantially all the trade in products originating ${ }^{4}$ in such territories." 5

Are these guidelines restricting the formation of welfare decreasing PTAs? The first condition above is hard to interpret. When there are many goods and many different tariffs or non-tariff barriers on trade, it is hard to define what more restrictive means in practice. It is well known that simple averages of tariffs and tariff equivalents of non-tariff barriers $(N T B s)$ are inadequate measures of this concept. In a series of recent papers, Anderson and Neary (1992b),(1990), and Anderson and Bannister (1992) define and implement an index of trade restrictiveness which could be applied to this issue. ${ }^{6}$

\footnotetext{
${ }^{4} \mathrm{By}$ originating is meant satisfying the rule of origin ( $\mathrm{ROO}$ ) requirement needed to confer origin. It can be argue that ROOs are what make FTAs acceptable to industry interests as they can in essence be set item by item. By making them very restrictive the domestic industry can be insulated from the consequences of the FTA. It is worth noting that over 200 pages of NAFTA have to do with ROOs!

5(GATT (1994), The Results of the Uruguay Round of Multilateral Trade Negotiation-The Legal Texts, Geneva: GATT Secretariat. pp. 523-524.)

${ }^{6}$ There are some restrictive asssumptions invloved in the implementation of their index. They
} 
Simpler criteria for restrictiveness are proposed by others. Bhagwati (1993) suggests that a common external tariff on each good set at the minimum of the pre $C U$ tariffs be seen as meeting this requirement. However, no analytical support for this is provided. In fact, as shown by $\mathrm{J} u$ and Krishna (1996), such reforms are exactly what occur with the creation of Free Trade Areas (FTAs) without Rules of Origin (ROOs) and such FTAs can reduce the welfare of members of the customs union as well as their imports, but not both!

McMillan (1993) suggests an alternative criterion with a distinctly mercantilistic flavor. He suggests that if a customs union raises the volume of trade with the rest of the world, then it should be allowed. This suggests that neither the customs union nor the rest of the world is hurt if trade volume rises. We examine the veracity of his hypothesis in Section 3.

Krugman (1991) argues that the creation of "natural trading blocs" 7 is bound to be desirable. Natural trading blocs are seen as being composed of trading partners who trade inordinately with each other. His argument goes as follows. If all trade took place within say a geographic area, then from standard trade theory it is clear that removal of trade barriers within this area is first best and must increase welfare. From this he goes on to say that for such natural partners,

assume implicit seperability of the difference between the expenditure and revenue function. This is not ensured by assuming implicit seperability of both the functions.

${ }^{7}$ The "natural trading partners" phrasing and hypothesis originated in Wonnacott and Lutz (1989). Summers (1991) also makes similar arguments. 
trading blocks are likely to be a good idea. Krugman explains: "To re-emphasize why this matters: if a disproportionate share of world trade would place within trading blocs even in the absence of any preferential trading arrangement, then the gain from trade creation within blocs are likely to outweigh any possible losses from external trade diversion."

These arguments are challenged by Bhagwati and Panagariya (1996) and Panagariya (1996). Their basic argument relies on the fact that large imports from a trading partner prior to the creation of the bloc also has a negative side in terms of the loss of tariff revenue due to the creation of the bloc. The more the country initially imports, the larger the tariff revenue loss due to the formation of the FTA. Thus, in the absence of redistribution within the FTA the "natural trading blocs" argument is turned on its head.

The natural trading blocs arguments are based on the volume of trade hypothesis originated by Lipsey (1970). In his words:

"On the one hand, the tariff is taken off imports from the country's union partner, and the relative price between these imports and domestic goods is brought into conformity with the real rate of transformation. This, by itself, tends to increase welfare. On the other hand, the relative price between imports from the union partner and imports from the outside world are moved away from equality with real rate of transformation. This by itself tends to reduce welfare."

He goes on to argue that the higher the proportion of trade is with the partner 
and the smaller the proportion of trade is with the outside world, the more likely is it that the first effect above which raises welfare will outweigh the second one which lowers welfare resulting in the FTA increasing welfare.

It is worthwhile formalizing Lipsey's argument. He considers the case where country $A$ imports goods from both country $B$ and country $C$. A uniform ad valorem tariff is assumed to be placed on all imported goods. Assume that $A$ and $B$ are small countries and that $A$ produces $x_{1}$ at home, imports $x_{2}$ from $B$ and imports $x_{3}$ from $C$, the rest of the world. The representative consumer has the utility function of $U=U\left(x_{1}, x_{2}, x_{3}\right)$. Let the world price of $x_{i}$ be $p_{i}^{w}(i=1,2,3)$. $p_{1}^{w}$ is normalized as 1 . The ad valorem tariff rates are given by $t_{i}$ for $x_{i}$ and $t_{1}$ is assumed to be zero. Then the domestic price $p_{i}=p_{i}^{w}\left(1+t_{i}\right)$. The total income of consumer is $I$ which equals expenditure, $x_{1}+p_{2}^{w} x_{2}+p_{3}^{w} x_{3}$, which is the budget balance condition. Thus:

$$
\begin{aligned}
& \frac{\partial U}{\partial x_{2}}=\frac{\partial U}{\partial x_{1}} p_{2}^{w}\left(1+t_{2}\right) \\
& \frac{\partial U}{\partial x_{3}}=\frac{\partial U}{\partial x_{1}} p_{3}^{w}\left(1+t_{3}\right)
\end{aligned}
$$

must hold. Equations (2.1) and (2.2) state that the marginal rates of substitution must equal domestic relative prices. Totally differentiating the utility function 
and the balance budget condition with respect to $t_{2}$ yields:

$$
\begin{gathered}
\frac{\partial U}{\partial t_{2}}=\frac{\partial U}{\partial x_{1}} \frac{\partial x_{1}}{\partial t_{2}}+\frac{\partial U}{\partial x_{2}} \frac{\partial x_{2}}{\partial t_{2}}+\frac{\partial U}{\partial x_{3}} \frac{\partial x_{3}}{\partial t_{2}} \\
\frac{\partial x_{1}}{\partial t_{2}}+p_{2}^{w} \frac{\partial x_{2}}{\partial t_{2}}+p_{3}^{w} \frac{\partial x_{3}}{\partial t_{2}}=0
\end{gathered}
$$

Substituting (2.4) into (2.3), we have

$$
\frac{\partial U}{\partial t_{2}}=\overbrace{\left[\frac{\partial U}{\partial x_{1}}-\frac{1}{p_{2}^{w}} \frac{\partial U}{\partial x_{2}}\right]\left[\frac{\partial x_{1}}{\partial t_{2}}\right]}^{(-)}+\overbrace{\left[\frac{\partial U}{\partial x_{3}}-\frac{p_{3}^{w}}{p_{2}^{w}} \frac{\partial U}{\partial x_{2}}\right]\left[\frac{\partial x_{3}}{\partial t_{2}}\right]}^{(+)}
$$

Assume that all goods are substitutes, so that $\frac{\partial x_{i}}{\partial t_{j}}>0$ for $i \neq j$. The first term in the right hand side of (2.5) represents the first effect brought out in Lipsey's argument above of bringing relative prices into conformity with the real rates of transformation. As the ratio of marginal utilities equals the domestic price ratio, $\frac{1}{p_{2}^{w}\left(1+t^{2}\right)}$, which is less than $\frac{1}{p_{2}^{w}}$, the first term in square brackets in $(2.5)$ is negative. Since goods are substitutes the first term works to raise welfare as $t_{2}$ is reduced. The second term in square brackets on the right hand side of (2.5) represents the effect of moving the relative price between imports from the union partner and imports from the outside world away from equality with real rates of transformation. This is zero if tariffs are equal on $B$ and $C$ to begin with and 
becomes positive as $t_{2}$ is reduced. Since goods are substitutes, the contribution of the second term is to reduce welfare as $t_{2}$ falls. If one adds to this the assumption that $\frac{\partial x_{i}}{\partial t_{2}}$ is likely to be large if $x_{i}$ is large, then welfare is likely to rise with the creation of a natural trading bloc between $A$ and $B$ as this is when the second effect will not dominate.

However, not only is there no basis for making this assumption, which is not an assumption on primitives, but making this very assumption as well as that of equal ad-valorem tariffs initially, but substituting slightly differently gives exactly the opposite result! If we substitute in terms of $\frac{\partial x_{3}}{\partial t_{2}}$ into (2.3), we get:

$$
\frac{\partial U}{\partial t_{2}}=\overbrace{\left[\frac{\partial U}{\partial x_{1}}-\frac{1}{p_{3}^{w}} \frac{\partial U}{\partial x_{3}}\right]\left(\frac{\partial x_{1}}{\partial t_{2}}\right)}^{(-)}+\overbrace{\left[\frac{\partial U}{\partial x_{2}}-\frac{p_{2}^{w}}{p_{3}^{w}} \frac{\partial U}{\partial x_{3}}\right]\left(\frac{\partial x_{2}}{\partial t_{2}}\right)}^{(+)}
$$

As before, the first term in the right hand side of (2.6) is negative so that this part raises welfare as $t^{2}$ is reduced. However, as the second term in square brackets is now negative, as is $\frac{\partial x_{2}}{\partial t_{2}}$, the second term in (2.6) is positive. Thus, this second term leads to a reduction in welfare as $t^{2}$ falls. Now, if $\frac{\partial x_{2}}{\partial t_{2}}$ is likely to be large if $x_{2}$ is large, as assumed by Lipsey, the second term dominates and welfare is likely to fall due to this customs union rather than rise!

What can we say from the above analysis? If the tariffs on the goods exported by $B$ and $C$ differ, the second term in (2.5) could be either positive or negative. It 
will be positive if $t^{3}>t^{2}$, and welfare will fall due to this term. It will be negative if $t^{3}<t^{2}$ so that welfare will rise due to this term. Hence, a FTA formed with the country on whom high tariffs are imposed will raise welfare, while one formed with the country on whom low tariffs are imposed could reduce welfare. This is of course in line with the concertina result in trade, which seems to be what is proven by the approach rather than any result on natural trading blocs!

Thus, when we ask for guidance on the question of which trading blocs should be allowed, or which reforms might be beneficial in general, theory seems to have little to offer.

\section{The Ex Post Approach}

While the framework below seems to only deal with tariffs it is more general. It can be seen as also representing a situation where quotas are present and all rents are appropriated domestically. In this case, the explicit tariffs should be re-interpreted as implicit ones arising from the quota. If some rents are not retained, then a parameter which weighs tariff revenues appropriately can capture this without changing the flavor of our results. We will assume factor supplies are fixed for simplicity. Extensions to variable factor supply are straightforward. Finally, although we deal with the single consumer case in the text, the extension to many agents is outlined in the Appendix. 
As a rule, we will index the time period by the use of a superscript. There are assumed to be $n$ goods $^{8}$, with prices $^{9}$ denoted by the column vector $P$. Let $P^{w i}$ and $P^{i}$ denote the world and domestic price vectors in time period $i$ respectively, where $i \in\{0,1\}$. In period $i$ specific tariffs are denoted by the vector $T^{i}$. The equivalent ad valorem tariffs are given by the vector $t^{i}$. Let $I_{t^{i}}$ denote the diagonal matrix with the elements of $t^{i}$ along the diagonal. Hence:

$$
P^{i}=P^{w i}+T^{i}=P^{w i}+I_{t^{i}} P^{w i}
$$

Assuming that tariff revenue is redistributed among consumers in a lump-sum fashion, the budget constraint for country $h$ may be written as:

$$
E^{h}\left(P^{h}, u^{h}\right)=R\left(P^{h}, V^{h}\right)+T^{h^{\prime}} M^{h}
$$

Where $E(\cdot)$ is the standard expenditure function of the country, $R(\cdot)$ is the revenue function, $u$ is the utility level, $V$ is the factor endowments vector. We assume that $E(\cdot)$ and $R(\cdot)$ have all the standard properties. $E_{p}($.$) and R_{p}($.$) are$ column vectors which represent the first partials of the expenditure and revenue

\footnotetext{
"These could be final or intermediate goods. Intermediate goods enter the output vector as negative elements and pure intermediate goods enter the demand vector as zcros.

${ }^{9}$ When it becomes necessary to distinguish between the variables for a number of countries we will use both subscripts and superscripts as needed. We will always denote partial derivatives by the use of subscripts. We will treat all vectors as column vectors and denote transposes by "', s.
} 
functions with respect to domestic prices. Thus, $E_{p}(P, u)=C(P, u)$ is demand, and $R_{p}(P, V)=X(P, V)$ is supply. $M()=.E_{p}()-.R_{p}($.$) is the net trade vector.$ World prices, and from them, the domestic prices, are determined by world market clearing conditions:

$$
\sum_{h \in H}\left[E_{p}^{h}\left(P^{h}, u^{h}\right)-R_{p}^{h}\left(P^{h}, V^{h}\right)\right]=0
$$

where $h$ indexes the country and $H$ the set of all countries. Thus, (3.1) and (3.2) can be used to solve for the endogenous variables in the system, namely equilibrium levels of utility and price.

\subsection{Sufficient Conditions}

We now turn to sufficient conditions for welfare to rise with tariff reform. These are based on the work of Ohyama (1972).

$$
\begin{aligned}
E\left(P^{1}, u^{1}\right) & =P^{1^{\prime}} C\left(P^{1}, u^{1}\right)+P^{1^{\prime}} C\left(P^{0}, u^{0}\right)-P^{1^{\prime}} C\left(P^{0}, u^{0}\right) \\
& \geq P^{1^{\prime}}\left[C\left(P^{1}, u^{1}\right)-C\left(P^{0}, u^{0}\right)\right]+E\left(P^{1}, u^{0}\right)
\end{aligned}
$$

Hence if: 


$$
\begin{aligned}
g^{1} & =P^{1^{\prime}}\left[C\left(P^{1}, u^{1}\right)-C\left(P^{0}, u^{0}\right)\right] \\
& >0
\end{aligned}
$$

then $u^{1}>u^{0}$.

This is the first form. It says that if the consumption bundle chosen before the reform is affordable at post reform prices than the reform is welfare enhancing. The argument is essentially a revealed preference one. If the new consumption bundle is chosen, when the old was available it must be because it is preferred to the old one. This is illustrated in Figure 1(a). If $C^{0}$ lies below the line going through $C^{1}$ with a slope corresponding to domestic price vector $P^{1}$ then the reform must be welfare improving.

Second, note that if $g^{1}>0$, then adding a negative number,

$$
-P^{1^{\prime}}\left[X\left(P^{1}, V\right)-X\left(P^{0}, V\right)\right]
$$

and requiring that this remain positive will also be a sufficient condition. Thus, another sufficient condition is that:

$$
P^{1^{\prime}}\left[M\left(P^{1}, u^{1}, V\right)-M\left(P^{0}, u^{0}, V\right)\right]>0
$$


This sufficient condition is illustrated in Figure 2(a). If $M^{0}$ lies below the $C C$ line, then welfare must have risen after the reform by revealed preference arguments.

For a small country, $P^{w 1}=P^{w 0}$. This together with the balanced trade condition gives:

$$
\begin{aligned}
P^{1^{\prime}}\left[M\left(P^{1}, u^{1}, V\right)-M\left(P^{0}, u^{0}, V\right)\right] & =\left(P^{w 1}+T^{1}\right)^{\prime}\left[M\left(P^{1}, u^{1}, V\right)-M\left(P^{0}, u^{0}, V\right)\right] \\
& =T^{1^{\prime}}\left[M\left(P^{1}, u^{1}, V\right)-M\left(P^{0}, u^{0}, V\right)\right]
\end{aligned}
$$

so that:

$$
T^{1^{\prime}}\left[M\left(P^{1}, u^{1}, V\right)-M\left(P^{0}, u^{0}, V\right)\right]>0
$$

is sufficient for $u^{1}>u^{0}$ for the small country case. In Figure $2(a)$ this condition corresponds to the requirement that $M^{0}$ lies below the $C C$ line. This ensures that the horizontal intercept for the line going through $M^{0}$ with slope corresponding to post reform domestic policies be below $t_{2}^{1} M_{2}^{1}$ so that (3.5) is met. The above conditions together give us:

Proposition 3.1. (Ohyama): A sufficient condition for the change in tariffs to be welfare improving is:

$$
P^{1^{\prime}}\left[C\left(P^{1}, u^{1}\right)-C\left(P^{0}, u^{0}\right)\right]>0
$$


or

$$
P^{1^{\prime}}\left[M\left(P^{1}, u^{1}, V\right)-M\left(P^{0}, u^{0}, V\right)\right]>0 \text {. }
$$

For a small country, which has balanced trade, it can be written as:

$$
T^{\mathbf{1}^{\prime}}\left[M\left(P^{1}, u^{1}, V\right)-M\left(P^{0}, u^{0}, V\right)\right]>0 .
$$

While Ohyama assumes a representative consumer, we show in the Appendix that these conditions hold more generally in the small country case.

\subsection{A Sufficient Condition for a Welfare Improving FTA}

What does this have to say about the welfare effects of free trade areas? Assume that the countries $A$ and $B$ form a free trade area and exclude the rest of the world $C$. From (3.4) an increase in the value of net imports of a country, evaluated at post FTA domestic prices, is sufficient for its welfare to rise. However, this does not mean that the volume of trade with the rest of the world rises, which is the condition suggested by McMillan (1993).

If we make the Armington assumption that all goods are differentiated by their country of origin, then goods can be divided into three mutually exclusive and exhaustive subsets. A good produced by country $K$ is indexed by $i \in I_{K}$, for 
$K \in\{A, B, C\} .{ }^{10}$ Those goods in $I_{K}$ are produced only by $K$ but are consumed by all countries. Now the creation of a FTA can be interpreted as changing the tariffs on the goods in $I_{B}$ to zero and leaving those on the goods in $I_{C}$ unchanged.

In the absence of export taxes, the tariffs on the goods in $I_{A}$ would be zero. Using (3.4) and noting that:

$T^{h 1^{\prime}}\left[M\left(P^{1}, u^{1}, V\right)-M\left(P^{0}, u^{0}, V\right)\right]=T_{C}^{h 1^{\prime}}\left[M_{C}^{h}\left(P^{h 1}, u^{h 1}, V^{h}\right)-M_{C}^{h}\left(P^{h 0}, u^{h 0}, V^{h}\right)\right]$, we have:

Proposition 3.2. Assume the countries $A$ and $B$ form an FTA. In the absence of export taxes, and with the Armington assumption, if

$$
\begin{aligned}
& T_{C}^{h 1^{\prime}}\left[M_{C}^{h}\left(P^{h 1}, u^{h 1}, V^{h}\right)-M_{C}^{h}\left(P^{h 0}, u^{h 0}, V^{h}\right)\right] \\
\geq & P^{w 1^{\prime}}\left[-M^{h}\left(P^{h 1}, u^{h 1}, V^{h}\right)\right]-P^{w 1^{\prime}}\left[-M^{h}\left(P^{h 0}, u^{h 0}, V^{h}\right)\right]
\end{aligned}
$$

then the formation of the FTA must increase the welfare of country $h$ in the FTA.

\footnotetext{
${ }^{11}$ Thus if the data came at some SIC level of aggregation, each SIC category would be composed of three subcategories and one sub category would be in each of the index sets defined above. One might think that the Armington assumption is not really needed here as goods could always be so disaggregated. We make it as in this case there are no issues about which goods are eligible for zero tariffs, ie, about origin.
} 
This basically says that if the increase in tariff revenue on imports from the rest of the world, valued at the tariffs after the $F T A$, is greater than the increase in the trade balance valued at world prices after the $F T A$, then the welfare of country $h$ must increase due to the formation of the FTA.

Corollary 3.3. For the small countries $A$ and $B$ who form an FT $A$ if:

$$
T_{C}^{h 1^{\prime}}\left[M_{C}^{h}\left(P^{h 1}, u^{h 1}, V^{h}\right)-M_{C}^{h}\left(P^{h 0}, u^{h 0}, V^{h}\right)\right] \geq 0
$$

and if there are no export taxes, then the formation of the FTA must increase the welfare of country $h$ in the $F T A^{11}$.

How about the welfare of a country outside the FTA? In the small country case, welfare of countries outside the FTA is unchanged as the prices facing them are unchanged. In the large country case, prices change due to the $F T A$ and so does welfare. Using (3.3) gives a sufficient condition for the welfare of the rest of

\footnotetext{
${ }^{11}$ If $A$ and $B$ are small countries, then $P^{w 1}=P^{w 0}$ so that $P^{w 1^{\prime}} M\left(P^{h 0}, u^{h 0}, V^{h}\right)=0$ since the value of net trade at world prices is zero as trade is balanced. Thus, the condition above simplifies to:

$$
T_{C}^{h 1^{\prime}}\left[M_{C}^{h}\left(P^{h 1}, u^{h 1}, V^{h}\right)-M_{C}^{h}\left(P^{h 0}, u^{h 0}, V^{h}\right)\right] \geq 0 .
$$

However, there is a tension between the small country assumption and the Armington Assumption. If products are differentiated by country of origin then it is hard to justify the small country assumption except as a convenient approximation.
} 
the world to rise to be that:

$$
P^{* 1^{\prime}}\left[C^{*}\left(P^{* 1}, u^{* 1}, V^{*}\right)-C^{*}\left(P^{* 0}, u^{* 0}, V^{*}\right)\right]>0
$$

or using (3.4) gives the condition to be:

$$
P^{* 1^{\prime}}\left[M^{*}\left(P^{* 1}, u^{* 1}, V^{*}\right)-M^{*}\left(P^{* 0}, u^{* 0}, V^{*}\right)\right]>0
$$

where ${ }^{*}$ ' denotes the equivalent variables for the rest of the world. That is, for the rest of the world as a whole, the value of their consumption or net import vector evaluated at their post $F T A$ domestic prices must rise after the $F T A$. Of course, since markets clear, imports from the rest of the world are the exports of the FTA, so that this is equivalent to saying that the value of net exports of the FTA, as a whole, appropriately priced, rising is sufficient for the welfare of the rest of the world to rise! Of course, this is not quite the same as the volume of trade rising.

Corollary 3.4. If the value of the consumption vector or the net import vector (evaluated at their post FTA domestic prices) for the rest of the world as a whole rises after the $F T A$, then their welfare must rise.

Of course, to the extent that the rest of the world is composed of many coun- 
tries, there is no guarantee that each country gains if this condition is satisfied.

\subsection{Necessary Conditions}

For any given country, we know that:

$$
\begin{aligned}
E\left(P^{0}, u^{0}\right) & =P^{0^{\prime}} C\left(P^{0}, u^{0}\right)-P^{0^{\prime}} C\left(P^{1}, u^{1}\right)+P^{0^{\prime}} C\left(P^{1}, u^{1}\right) \\
& \geq P^{0^{\prime}}\left[C\left(P^{0}, u^{0}\right)-C\left(P^{1}, u^{1}\right)\right]+E\left(P^{0}, u^{1}\right)
\end{aligned}
$$

If $g_{2}=P^{0^{\prime}}\left[C\left(P^{0}, u^{0}\right)-C\left(P^{1}, u^{1}\right)\right] \geq 0$, then welfare must fall due to the tariff reform from $T^{0}$ to $T^{1}$. Thus, for welfare to rise, it is necessary that $g_{2}<0$ or:

$$
P^{0^{\prime}}\left[C\left(P^{0}, u^{0}\right)-C\left(P^{1}, u^{1}\right)\right]<0
$$

This says that a necessary condition for reform to be welfare improving is that the new consumption bundle not be affordable at the old prices. This is depicted in Figure $1(b)$. The point $C^{0}$ gives the old consumption bundle. If $C^{1}$, the new consumption bundle, lies below the line with a slope corresponding to the old price vector, and going through $C^{0}$, denoted by $A A$, then welfare must fall due to the reform. The argument is essentially a revealed preference one. $C^{1}$ in this case is affordable when $C^{0}$ is chosen and so must not be preferable to it. Of course, 
$C^{1}$ being above the line does not ensure that the reform is welfare enhancing.

Note that if $g_{2}<0$, is a necessary condition, so is $g_{2}-A<0$ for $A>0$. Thus,

$$
P^{0^{\prime}}\left[C\left(P^{0}, u^{0}\right)-C\left(P^{1}, u^{1}\right)\right]-P^{0^{\prime}}\left[X\left(P^{0}, V\right)-X\left(P^{1}, V^{1}\right)\right]<0
$$

is also necessary. Hence an alternative form of the necessary condition for welfare to rise due to the reform is that:

$$
P^{0^{\prime}}\left[M\left(P^{0}, u^{0}, V\right)-M\left(P^{1}, u^{1}, V\right)\right]<0
$$

This can be illustrated as done in Figure 2(b). Here the net trade vector is drawn as are the usual trade indifference curves. Good 2 is the imported good and we assume that there is no tax on exports. The necessary condition above boils down to $M^{1}$ lying above the line going through $M^{0}$ with slope corresponding to $P^{0}$ along $A A$ but being above $B B$. This has the same revealed preference argument, but made in net trade space as earlier.

A third form is also useful. However, this third form is valid only in the small country case.

$$
P^{0^{\prime}}\left[M\left(P^{0}, u^{0}, V\right)-M\left(P^{1}, u^{1}, V\right)\right]=P^{w 0^{\prime}}\left[M\left(P^{0}, u^{0}, V\right)-M\left(P^{1}, u^{1}, V\right)\right]
$$




$$
\begin{array}{r}
+T^{0^{\prime}}\left[M\left(P^{0}, u^{0}, V\right)-M\left(P^{1}, u^{1}, V\right)\right] \\
=T^{0^{\prime}}\left[M\left(P^{0}, u^{0}, V\right)-M\left(P^{1}, u^{1}, V\right)\right]
\end{array}
$$

since for a small country, world prices are given so that $P^{w 0}=P^{w 1}$ and trade is balanced. Hence, for a small country to gain from the tariff reform, it is necessary for:

$$
T^{0^{\prime}}\left(M\left(P^{0}, u^{0}, V\right)-M\left(P^{1}, u^{1}, V\right)\right)<0 .
$$

This condition is depicted in Figure $2(b)$ as well. In Figure $2(b)$, the $B B$ line gives the locus of net trades whose value at domestic prices equals that of $M^{0}$. Its horizontal intercept equals $t_{2}^{0} M_{2}^{0}$ and vertical intercept, equals $\frac{t_{2}^{0} M_{2}^{0}}{P_{2}^{0}}$. As world prices are fixed for a small country, $M^{1}$ must lie on the line $A A$ through the origin with slope determined by world prices. If it lies below $M^{0}$ along $A A$, then the reform must reduce welfare. But this corresponds to the intercept on the horizontal axis falling, that is, $t_{2}^{0} M_{2}^{1}<t_{2}^{0} M_{2}^{0}$. Thus, $t_{2}^{0} M_{2}^{1}>t_{2}^{0} M_{2}^{0}$ is necessary for welfare to rise due to the reform. Note that this form provides a link between our analysis and that of Bhagwati and Panagariya (1996) and Panagariya (1996). Our results show that if at the pre-reform tariffs, tariff revenue post reform would have fallen short of pre-reform levels, the reforms could not have raised welfare! Our results here are summarized below. 
Proposition 3.5. A neccesary condition for the change in tariffs to be welfare improving is that:

$$
P^{0^{\prime}}\left[C\left(P^{0}, u^{0}\right)-C\left(P^{1}, u^{1}\right)\right]<0
$$

or

$$
P^{0^{\prime}}\left[M\left(P^{0}, u^{0}, V\right)-M\left(P^{1}, u^{1}, V\right)\right]<0 .
$$

For a small country, this can be written as:

$$
T^{0^{\prime}}\left(M\left(P^{0}, u^{0}, V\right)-M\left(P^{1}, u^{1}, V\right)\right)<0
$$

\subsection{Application to FTAs}

A necessary condition for welfare improvement in country $A$ due to the formation of an FTA under the Armington assumption can now be written as:

$$
\begin{aligned}
& P_{A}^{A 0^{\prime}}\left[M_{A}^{A}\left(P^{A 0}, u^{A 0}, V^{A}\right)-M_{A}^{A}\left(P^{A 1}, u^{A 1}, V^{A}\right)\right] \\
& +P_{B}^{A 0^{\prime}}\left[M_{B}^{A}\left(P^{A 0}, u^{A 0}, V^{A}\right)-M_{B}^{A}\left(P^{A 1}, u^{A 1}, V^{A}\right)\right] \\
& +P_{C}^{A 0^{\prime}}\left[M_{C}^{A}\left(P^{A 0}, u^{A 0}, V^{A}\right)-M_{C}^{A}\left(P^{A 1}, u^{A 1}, V^{A}\right)\right] \\
& \leq 0 .
\end{aligned}
$$


The above expression can be rewritten as

$$
\begin{aligned}
& P_{B}^{A 0^{\prime}}\left[M_{B}^{A}\left(P^{A 1}, u^{A 1}, V^{A}\right)-M_{B}^{A}\left(P^{A 0}, u^{A 0}, V^{A}\right)\right] \\
\geq & P_{A}^{A 0^{\prime}}\left[\left(-M_{A}^{A}\left(P^{A 1}, u^{A 1}, V^{A}\right)\right)-\left(-M_{A}^{A}\left(P^{A 0}, u^{A 0}, V^{A}\right)\right)\right] \\
& -P_{C}^{A 0^{\prime}}\left[M_{C}^{A}\left(P^{A 1}, u^{A 1}, V^{A}\right)-M_{C}^{A}\left(P^{A 0}, u^{A 0}, V^{A}\right)\right]
\end{aligned}
$$

This gives us the following result:

Corollary 3.6. Under the Armington assumption, if the increase in the value of imports from the partner country, valued at pre FTA domestic prices, is less than the difference between the increase in the value of exports and the increase in the value of the imports from the rest of the world due to the FTA, then the welfare of the country must fall. ${ }^{12}$

For example, if U.S. imports from the rest of the world fall due to NAFTA (so that the third term in (3.11) is positive) and U.S. exports rise or are constant, (so that the second term in (3.11) is positive) then a necessary condition for U.S. welfare to rise is that imports from its partner country rises. In fact, imports from Mexico by the U.S. have significantly increased after $N A F T A$. While public

\footnotetext{
${ }^{12}$ In a way, making the Armington Assumption here in order to derive a stronger condition to be applied to FTAs is less illuminating here as imports are being evaluated at pre- FTA prices so that tarifs on FTA members are not zero.
} 
opinion concerning this increase in imports is generally negative, the U.S. would suffer a welfare loss due to NAFTA if such an increase of imports did not occur!

\subsection{World Welfare and a Proposal for Reforming Article XXIV}

A major concern regarding trade reform is that the rest of the world may be hurt by it. Article $X X I V$ of the GATT reflects such concerns. Ohyama (1972) studies the sufficient conditions for world gains from trade reform assuming that a world government coordinates all the functions of national governments and provides the needed redistribution among nations. Srinivasan (1996) studies the same question using the Kemp-Wan approach and derives the required common external tariff in some special cases.

Sufficient and necessary conditions for the rest of the world to gain from reform in any country or subset of countries arise naturally from our approach. Using the conditions given in (3.6) or (3.7) country by country yields the required sufficient conditions for their welfare to rise. However, this may be viewed as too strong a requirement. After all, one might argue, these conditions are not necessary for welfare to rise so that this requirement could rule out reform which was Pareto improving. A weaker requirement might be that no country necessarily loses from the reform. We turn to this next.

Consider a world with $M$ countries indexed by $h$, each of which has tariffs $T^{\text {hi }}$ 
in period $i, i \in[0,1]$. Then, if all countries met the necessary conditions for the change in tariffs to be welfare improving, it must be the case that:

$$
\sum_{h=1}^{M} P^{h 0^{\prime}}\left[M^{h}\left(P^{h 0}, u^{h 0}, V^{h}\right)-M^{h}\left(P^{h 1}, u^{h 1}, V^{h}\right)\right] \leq 0
$$

Thus, if it were the case that:

$$
\sum_{h=1}^{M} P^{h 0^{\prime}}\left[M^{h}\left(P^{h 0}, u^{h 0}, V^{h}\right)-M^{h}\left(P^{h 1}, u^{h 1}, V^{h}\right)\right]>0
$$

then there must exist some countries who lose from the reform. The above inequality can be written as

$$
\begin{aligned}
& \sum_{h=1}^{M} T^{h 0^{\prime}}\left[M^{h}\left(P^{h 0}, u^{h 0}, V^{h}\right)-M^{h}\left(P^{h 1}, u^{h 1}, V^{h}\right)\right] \\
& +P^{w 0^{\prime}}\left[\sum_{h=1}^{M} M^{h}\left(P^{h 0}, u^{h 0}, V^{h}\right)-\sum_{h=1}^{M} M^{h}\left(P^{h 1}, u^{h 1}, V^{h}\right)\right]
\end{aligned}
$$

$>0$.

The above, (3.12), together with the world market clearing conditions (which require that the sum of net imports across all countries be zero) gives: 
Proposition 3.7. If

$$
\alpha=\sum_{h=1}^{M} P^{h 0^{\prime}}\left[M^{h}\left(P^{h 0}, u^{h 0}, V^{h}\right)-M^{h}\left(P^{h 1}, u^{h 1}, V^{h}\right)\right]>0
$$

or

$$
\beta=\sum_{h=1}^{M} T^{h 0 t}\left[M^{h}\left(P^{h 0}, u^{h 0}, V^{h}\right)-M^{h}\left(P^{h 1}, u^{h 1}, V^{h}\right)\right]>0
$$

then at least one country must lose from the reforms.

The reform of Article $X X I V$ has attracted attention largely because of a revived interest since the late eighties in FTAs and other PTAs. The proposals by Bhagwati (1993), McMillan (1993), and Srinivasan (1996) were discussed above. Our results suggest that requiring that the indices $\alpha$ and $\beta$ defined above be positive can be seen as a weak safeguard for the rest of the world and that (3.6) or (3.7) being met be seen as strong safeguards for the rest of the world.

\section{Conclusion}

Our results so far suggest that there may be a way of checking ex post, whether welfare has risen or fallen due to a set of trade reforms. For example, the second form of the necessary and of the sufficient conditions for welfare to rise post reform show that if the value of the net trade vector at the post trade reform domestic 
prices rises, then welfare must rise. If the value of the net trade vector at the pre trade reform domestic prices falls, then welfare must fall.

Two aspects of our results here are worth emphasizing. First, our approach also applies to countries which are not undertaking any reform themselves, but are affected by the reforms of other large countries. For example, we could use our approach to see if countries outside the FTA gain or lose from its creation. This could help in reforming Article $X X I V$ of $G A T T$. Second, it is worth emphasizing that our approach cannot provide a complete ranking over all outcomes. For example, if the value of the net trade vector at the post trade reform domestic prices falls, welfare may rise or fall. Hence, our results provide at best only a partial ordering among outcomes. Many outcomes are not comparable. Never the less, as applying them seems to require readily available data, it may well be worth doing.

\section{Appendix: The Many Consumer Case}

In all our results so far, we have assumed that there is a representative consumer. In this Appendix we relax this assumption to look for conditions under which our results are more generally applicable. The approach is based on that of Dixit and Norman (1980), (1986). We will sketch the proofs, rather than do them very formally as they proceed along fairly standard lines once the initial connections 
are made. If lump sum taxes are available, then there is a fairly simple condition which needs to be satisfied for the reform to be potentially welfare improving.

\subsection{Lump Sum Taxes}

Let $C^{h}\left(P, W, u^{h}\right)$ and $V^{h}\left(P, W, u^{h}\right)$ denote the consumption and factor supply of household $h$, while $P$ and $W$ denote the prices they face. Define $E^{* h}(P, W, u)$ to be the minimum lump sum transfer/tax needed to keep household $h$ at utility level $u$. Thus:

$$
E^{* h}\left(P, W, u^{h}\right)=P^{\prime} C^{h}\left(P, W, u^{h}\right)-W^{\prime} V^{h}\left(P, W, u^{h}\right)
$$

Similarly, let $X(P, W)$ and $V(P, W)$ denote the output of goods and demand for factors by firms. Firms maximize profits and

$$
R^{*}(P, W)=P^{\prime} X(P, W)-W^{\prime} V(P, W)
$$

defines the maximized value of profits. ${ }^{13}$ The rest of the world excess supply, when the domestic price is $P$ and specific tariffs are $T$, is given by $M(P, T)$.

\footnotetext{
${ }^{13}$ All the usual envelope results apply so that $E_{P}^{* h}\left(P, W, u^{h}\right)=C^{h}\left(P, W, u^{h}\right), E_{W}^{* h}\left(P, W, u^{h}\right)=$ $-V^{h}\left(P, W, u^{h}\right), R_{P}^{*}(P, W)=X(P, W), R_{W}^{*}(P, W)=-V(P, W)$.
} 
Equilibrium is given by:

$$
\begin{aligned}
\sum_{h} E_{P}^{* h}\left(P, W, u^{h}\right) & =R_{P}^{*}(P, W)+M(P, T) \\
\sum_{h} E_{W}^{* h}\left(P, W, u^{h}\right) & =-V(P, W) \\
E^{* h}\left(P, W, u^{h}\right) & =0 .
\end{aligned}
$$

These state that goods markets clear internationally, factor markets clear nationally, and there are no lump sum transfers. They determine the vectors $u, P$ and $W$ in the absence of any policies. If taxes and tariffs are in place, then the only difference is that lump sum transfers are restricted to ensure that they do not exceed earnings of the government through the taxes and tariffs and $P$ refers to domestic prices which differ from world prices by the tariffs.

Let $u^{0} P^{0}$ and $W^{0}$ be the equilibrium domestic utility, price and wage vectors when tariffs are $T^{0}$. Let $u^{1} P^{1}$ and $W^{1}$ be the equilibrium domestic utility, price and wage vectors when tariffs are $T^{1}$. Let tariffs be fixed at $T^{1}$. We wish to know whether there exists a set of lump sum taxes and transfers which will make all households at least as well off as they were under $T^{0}$. To do so, we will construct a policy which keeps each household at $u^{h 0}$ and check if it is feasible.

Consider a policy by government to impose lump sum taxes/transfers as needed to keep each individual $h$ at the utility level $u^{h 0}$. The government then 
spends an equal amount of its net revenue on each good. This defines the vector of government demands $g$ where the i'th element of $g, g^{i}$ is given by the rule that expenditure on all goods is the same. Thus:

$$
g^{i}=\frac{T^{1^{\prime}} M\left(P, T^{1}\right)-\sum_{h} E^{* h}\left(P, W, u^{h 0}\right)}{n p^{i}}
$$

where $n$ is the number of goods. In this case, equilibrium $P$ and $W$, denoted by $P^{e}$ and $W^{e}$, are determined by:

$$
\begin{aligned}
\sum_{h} E_{P}^{* h}\left(P^{e}, W^{e}, u^{h 0}\right)+g & =R_{P}^{*}\left(P^{e}, W^{e}\right)+M\left(P^{e}, T^{1}\right) \\
\sum_{h} E_{W}^{* h}\left(P^{e}, W^{e}, u^{h 0}\right) & =R_{W}^{*}\left(P^{e}, W^{e}\right)=-V\left(P^{e}, W^{e}\right)
\end{aligned}
$$

while $u^{h}=u^{h 0}$.

This policy is feasible if government net revenue $(G N R)$ is positive, where

$$
G N R=T^{1^{\prime}} M\left(P^{e}, T^{1}\right)-\sum_{h} E^{* h}\left(P^{e}, W^{e}, u^{h 0}\right)
$$

Recall that:

$$
\begin{aligned}
\sum_{h} E^{* h}\left(P^{e}, W^{e}, u^{h}\right) & \leq \sum_{h}\left[P^{e^{\prime}} C^{* h}\left(P^{0}, W^{0}, u^{h 0}\right)-W^{e^{\prime}} V^{h}\left(P^{0}, W^{0}, u^{h 0}\right)\right] \\
& =P^{e^{\prime}}\left[X\left(P^{0}, W^{0}\right)+M\left(P^{0}, T^{0}\right)\right]-W^{e^{\prime}} V\left(P^{0}, W^{0}\right)
\end{aligned}
$$




$$
\begin{aligned}
& \leq P^{e^{\prime}} X\left(P^{e}, W^{e}\right)-W^{e^{\prime}} V\left(P^{e}, W^{e}\right)+P^{e t} M\left(P^{0}, T^{0}\right) \\
& =R^{*}\left(P^{e}, W^{e}\right)+P^{e^{\prime}} M\left(P^{0}, T^{0}\right) \\
& =P^{e^{\prime}} M\left(P^{0}, T^{0}\right) .
\end{aligned}
$$

From (5.1), constant returns to scale, and balanced trade, it, follows that:

$$
\begin{aligned}
G N R & =T^{1^{\prime}} M\left(P^{e}, T^{1}\right)-\sum_{h} E^{* h}\left(P^{e}, W^{e}, u^{h 0}\right) \\
& \geq T^{1^{\prime}} M\left(P^{e}, T^{1}\right)-P^{e^{\prime}} M\left(P^{0}, T^{0}\right) \\
& =P^{e^{\prime}}\left[M\left(P^{e}, T^{1}\right)-M\left(P^{0}, T^{0}\right)\right] .
\end{aligned}
$$

Thus, $P^{e^{\prime}}\left[M\left(P^{e}, T^{1}\right)-M\left(P^{0}, T^{0}\right)\right]>0$ is sufficient for potential Pareto improvements to exist in the presence of lump sum taxes and transfers. Recall that (3.4) was the sufficient condition for reform to be welfare improving in the single consumer case. Our condition for a potential Pareto improvement differs from this as $P^{1}$ is replaced by $P^{e}$ in the formula. In general, $P^{e}$ is not readily observable. However, for the small country case, world prices are given and denoted by $P^{w}$, so that $P^{e}$ equals $P^{w}+T^{1}=P^{1}$ ! Hence, in the small country case our single consumer condition works. 


\subsection{Non Lump Sum Taxes}

What about the possibility of Pareto improvements without lump sum transfers? The approach is to show that under certain conditions, identified below, the trade possibility set post reform contains a point strictly above the pre-reform point for consumers. This pre-reform point is labelled with a superscript ' ${ }^{\circ}$. To do so, an artificial economy with the same trade and production possibilities, but with preferences of the fixed coefficients form, displaced by the pre-reform consumption point is constructed. This, the initiated will recall, is the key to constructing the equilibrium without lump sum taxes. The proof then proceeds along the usual lines. Producer taxes/subsidies are applied which leave producers and the rest of the world facing prices which were the equilibrium for the artificial economy. Hence they do not change their behavior so that total supply is what it was for the artificial economy. But consumers face pre-reform prices for goods and factors and so get pre-reform utility. Hence, their behavior is as it was before the reform. The government buys the gap in production and consumption, which is positive if certain conditions are met.

The procedure consists of two stages. First find taxes to support the prereform levels of utility. Then we do better than this. 


\subsubsection{Stage 1:}

Construct the artificial economy so that it has the same production and trade possibilities as the existing domestic one, but has preferences given by fixed coefficient preferences radiating out along the $45^{\circ}$ line from the pre-reform point chosen by consumers. Tariffs are set at post reform levels. If the equilibrium of this economy has the hypothetical consumer of the artificial economy at a point that lies strictly above the pre-reform point, our requirements are met.

Let $P^{o}$ be the pre-reform domestic price (for the $n$ goods and $m$ factors) vector. Let $X^{0}$ be the pre-reform net supply vector. A positive element denotes output produced and a negative one denotes inputs used. $C^{h}\left(P^{0}\right)$ is the demand function of consumer $h$. Positive numbers denote demands for goods and negative numbers denote supplies of factors. Let:

$$
C^{0} \equiv C\left(P^{0}\right)=\sum_{h} C^{h}\left(P^{0}\right)
$$

denote the aggregate demand vector in the pre-reform equilibrium.

Let $I=\{1, \ldots n\}$ be the index set for $n$ goods.

$$
U(C)=\min _{i \in I}\left[C^{i}-C^{i o}\right]
$$


defines the preferences of the hypothetical consumer in the artificial economy. Let $P$ be normalized so that $\sum_{i} P^{i}=1$.

Equilibrium for the artificial economy is a price vector, $P^{e}$ such that:

$$
\begin{aligned}
X\left(P^{e}\right)+M\left(P^{e}, T^{1}\right) & \geq C\left(P^{e}\right) \\
P^{e^{\prime}}\left[C\left(P^{e}\right)-X\left(P^{e}\right)-M\left(P^{e}, T^{1}\right)\right] & =0
\end{aligned}
$$

so that supply does not exceed demand, and if it does, price is zero, which is the associated complementary slackness condition, and consumers and producers are doing the best they can, that is, maximizing their objective functions subject to their constraints. From trade balance:

$$
P^{e^{\prime}} C\left(P^{e}\right)=P^{e^{\prime}} X\left(P^{e}\right)+T^{1^{\prime}} M\left(P^{e}, T^{1}\right)
$$

so that income equals expenditure,

As preferences are of the fixed coefficients form as given, an equal additional amount of each good is chosen by the hypothetical consumer in the artificial economy. ${ }^{14}$ Hence:

\footnotetext{
${ }^{14}$ Of course, this additional amount could be negative. However, we show that it is positive if certain conditions are met.
} 


$$
C\left(P^{e}\right)=C^{0}+\Delta i
$$

where $i$ is an $(n+m)$ by 1 vector of ones and $\Delta$ is a scalar which we show is positive.

Since the value of net trade at world prices is zero, by (5.5) and the normalization rule on prices,

$$
\begin{aligned}
P^{e^{\prime}} C\left(P^{e}\right) & =P^{e^{\prime}} C^{0}+\Delta \\
& =P^{e^{\prime}}\left[X\left(P^{0}\right)+M\left(P^{0}, T^{0}\right)\right]+\Delta
\end{aligned}
$$

Also, by (5.4)

$$
P^{e^{\prime}} C\left(P^{e}\right)=P^{e^{\prime}} X\left(P^{e}\right)+T^{1^{\prime}} M\left(P^{e}, T^{1}\right) .
$$

Hence from (5.5) and (5.4):

$$
\begin{aligned}
\Delta= & P^{e^{\prime}}\left[X\left(P^{e}\right)-X\left(P^{0}\right)\right] \\
& +T^{1^{\prime}} M\left(P^{e}, T^{1}\right)-P^{e^{\prime}} M\left(P^{0}, T^{0}\right) \\
= & P^{e^{\prime}}\left[X\left(P^{e}\right)-X\left(P^{0}\right)\right] \\
& +T^{1^{\prime}} M\left(P^{e}, T^{1}\right)-\left(P^{w e}+T^{1}\right)^{\prime} M\left(P^{0}, T^{0}\right)
\end{aligned}
$$




$$
\begin{aligned}
& =P^{1^{\prime}}\left[X\left(P^{1}\right)-X\left(P^{0}\right)\right]+T^{1^{\prime}}\left[M\left(P^{1}, T^{1}\right)-M\left(P^{0}, T^{0}\right)\right]-P^{w^{\prime}} M\left(P^{0}, T^{0}\right) \\
& =P^{1^{\prime}}\left[X\left(P^{1}\right)-X\left(P^{0}\right)\right]+T^{1^{\prime}}\left[M\left(P^{1}, T^{1}\right)-M\left(P^{0}, T^{0}\right)\right]
\end{aligned}
$$

in the small country case. Recall that in this case, $P^{w e}=P^{w 1}=P^{w 0}=P^{w}$, so that $P^{e}=P^{w}+T^{1}=P^{1}$.

Since the first term, $P^{1^{\prime}}\left[X\left(P^{1}\right)-X\left(P^{0}\right)\right] \geq 0$ due to profit maximization, if the second term, $T^{\mathbf{1}^{\prime}}\left[M\left(P^{1}, T^{1}\right)-M\left(P^{0}, T^{0}\right)\right]>0$, then $\Delta>0$. In this event, the equilibrium for the artificial economy lies strictly outside the pre-reform one.

Now define taxes so that consumers face pre-reform prices, $P^{0}$, producers face artificial economy prices, $P^{1}$, and government buys any slack. Hence:

$$
g=X\left(P^{1}\right)+M\left(P^{1}, T^{1}\right)-C\left(P^{0}\right)
$$

Set taxes, $t$, such that the prices producers face plus the taxes equal the consumer prices. Thus,

$$
P^{1}+t=P^{0}
$$

By definition the market clears.

What about government expenditure relative to revenue? Government expen- 
diture equals:

$$
\begin{aligned}
P^{1} g^{1} & =P^{1^{\prime}} M\left(P^{1}, T^{1}\right)+P^{1^{\prime}} X\left(P^{1}\right)-P^{1^{\prime}} C\left(P^{0}\right) \\
& =T^{1^{\prime}} M\left(P^{1}, T^{1}\right)-P^{1^{\prime}} C\left(P^{0}\right) \\
& =T^{1^{\prime}} M\left(P^{1}, T^{1}\right)-P^{1^{\prime}} C\left(P^{0}\right)+P^{0^{\prime}} C\left(P^{0}\right)-P^{0^{\prime}} C\left(P^{0}\right) \\
& =T^{1^{\prime}} M\left(P^{1}, T^{1}\right)+\left(P^{0}-P^{1}\right)^{\prime} C\left(P^{0}\right)-P^{0^{\prime}} C\left(P^{0}\right)+P^{0^{\prime}} X\left(P^{0}\right) \\
& =T^{1^{\prime}} M\left(P^{1}, T^{1}\right)+t^{\prime} C\left(P^{0}\right)-P^{0^{\prime}} M\left(P^{0}, T^{0}\right) \\
& =T^{1^{\prime}} M\left(P^{1}, T^{1}\right)+t^{\prime} C\left(P^{0}\right)-T^{0^{\prime}} M\left(P^{0}, T^{0}\right)
\end{aligned}
$$

as $P^{0^{\prime}} X\left(P^{0}\right)=P^{1} X\left(P^{1}\right)=0$ and $P^{w^{\prime}} M\left(P^{1}, T^{1}\right)=P^{w^{\prime}} M\left(P^{0}, T^{0}\right)=0$. In other words, government expenditure on purchases plus government redistribution of pre-reform tariff revenues equals revenue from tariffs and taxes. Hence, the government budget balances.

\subsubsection{Stage 2:}

This second step consists of perturbing the tax policies so that all agents gain, and having the government buy the remaining positive surplus. Such perturbations are possible, for example, if prices are in the interior of the simplex and consumers are on the same side of some market. If they are net buyers in this market, the price should be reduced, if net sellers, the price should be raised. The arguments 
are standard by now and we direct the reader to Dixit and Norman (1986) for details. 


\section{References}

[1] Anderson, J. E. and G. Bannister (1992): "The Trade Restrictiveness Index: An Application to Mexican Agriculture," World Bank Policy Research Working Papers in International Trade No. WPS874, Washington, D.C.: The World Bank.

[2] Anderson, J. E. and J. P. Neary (1990), "The Coefficient of Trade Utilization: Back to the Baldwin Envelope," in R. W. Jones and A. O. Krueger (eds.): The Political Economy of International Trade: Essays in Honour of Robert Baldwin, Oxford: Basil Blackwell, 49-72.

[3] Anderson, J. E. and J. P. Neary (1992a): "Trade Reform with Quotas, Partial Rent Retention and Tariffs," Econometrica, 60, 57-76.

[4] Anderson, J. E. and J. P. Neary (1992b): "A New Approach to Evaluating Trade Policy," World Bank Policy Research Working Papers in International Trade No. WPS1022, Washington, D.C.: The World Bank, November.

[5] Bhagwati, J. and A. Panagariya (1996), "Preferential Trading Areas and Multilateralism: Strangers, Friends or Foes?" mimeo.

[6] Bhagwati, J. (1993), "Regionalism and Multilateralism: An Overview," pp. 22-51 in New Dimensions in Regional Integration, De Melo, J. and A. Pana- 
gariya (Ed.), Cambridge University Press.

[7] Dixit, Avinash and Victor Norman, (1980). Theory of International Trade. Cambridge University Press.

[8] Dixit, Avinash and Victor Norman, (1986). "Gains from Trade Without Lump Sum Compensation." Journal of International Economics, 21: 111122.

[9] Falvey, Rodney (1988) "Tariffs, Quotas and Piecemeal Policy Reform" Journal of International Economics 25: 177-188.

[10] Frankel, J., E. Stein and S. Wei (1995), "Trading Blocs and the Americas: The Natural, the Unnatural and the Supernatural," Journal of Development Economics, June 1995.

[11] Ju, J. and K. Krishna (1996), "Market Access and Welfare Effects of Free Trade Areas without Rules of Origin," NBER Working Paper No. 5480.

[12] Krugman, P. (1991), "The Move to Free Trade Zones," in Policy Implications of Trade and Currency Zones, symposium sponsored by the Federal Reserve Bank of Kansas.

[13] Lipsey, R. (1970), "The Theory of Customs Union: A General Equilibrium Analysis", London School of Economics, Research Monograph, 7, London. 
[14] Lopez, Ramon and A. Panagariya (1992) "On the Theory of Piecemeal Policy Reform: The Case of Pure Intermediate Inputs," American Economic Review 82: 615-625.

[15] McMillan, J. (1993), "Does Regional Integration Foster Open Trade? Economic Theory and GATT's Article XXIV," in Regional Integration and the Global Trading System, Anderson, K. and R. Blackhurst (eds.), St. Martin's Press.

[16] Ohyama, M. (1972), Trade and Welfare in General Equilibrium", Keio Economic Studies, $9(2)$, pp. 37-73.

[17] Panagariya, Arvind (1996), "Preferential Trading and the Myth of Natural Trading Partners," University of Maryland, mimeo.

[18] Srinivasan, T. N. (1996), "The Common External Tariff of a Customs Union: Alternative Approaches," mimeo.

[19] Summers, L. (1991) "Regionalism and the World Trading System," in Policy Implications of Trade and Currency Zones, symposium sponsored by the Federal Reserve Bank of Kansas City.

[20] Turunen-Red, Arja H. and A. D. Woodland (1990) "Multilateral Reform of Domestic Taxes," Oxford Economic Papers 42, pp. 160-186. 
[21] Turunen-Red, Arja H. and A. D. Woodland (1991) "Strict Pareto-Improving Multilateral Reforms of Tariffs," Econometrica 59, July, pp. 1127-1152.

[22] Wonnacott, Paul and M. Lutz (1989) "Is There a Case for Free Trade Areas?" in Schott, Jeffrey, Free Trade Areas and U. S. Trade Policy, Washington, D.C.: Institute for International Economics, 59-84. 
Figure 1(a)

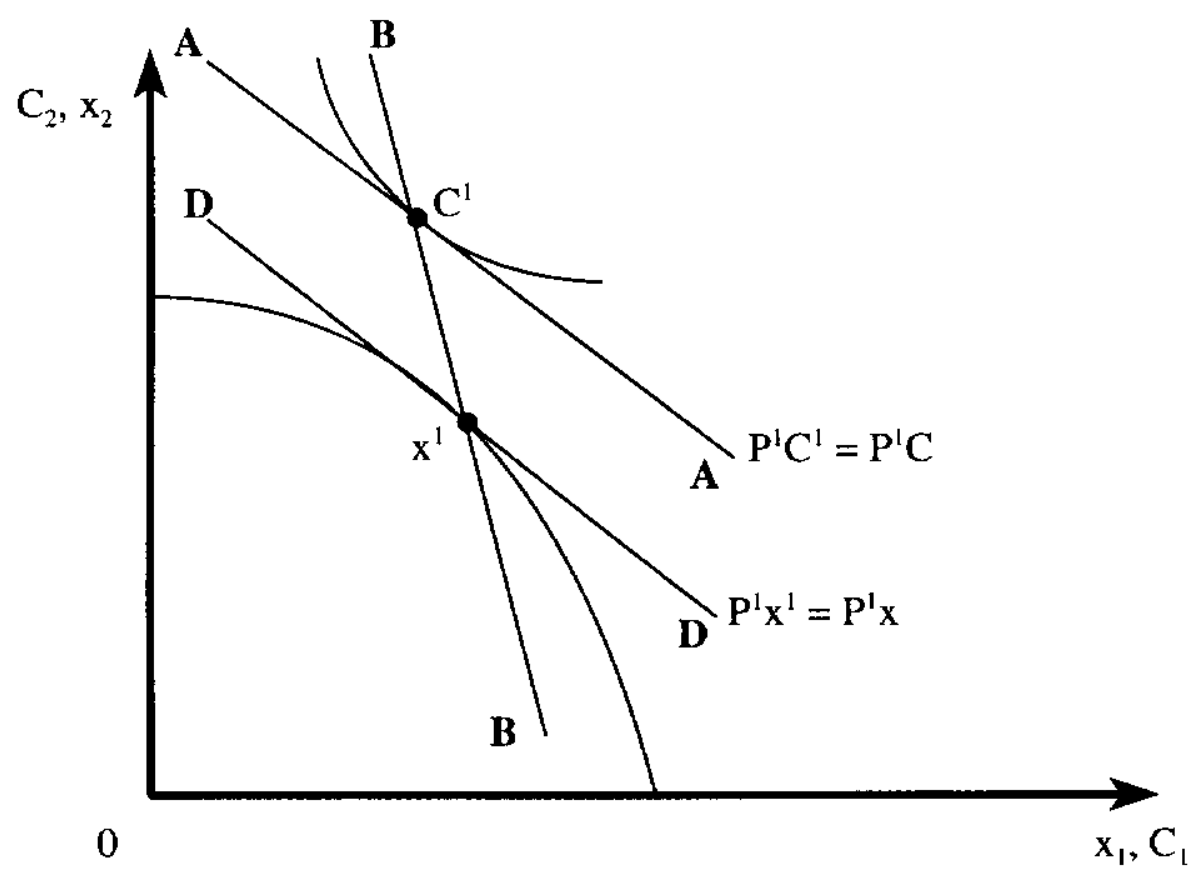

Figure 1(b)

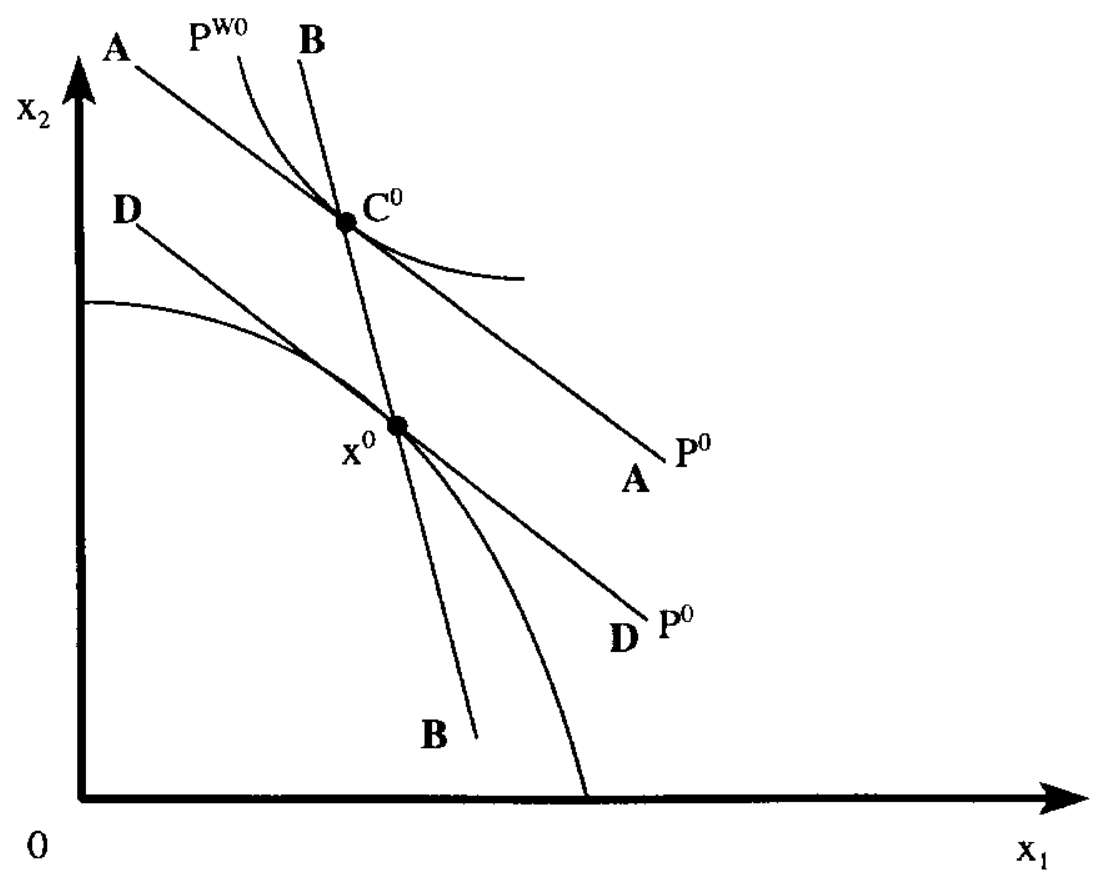


Figure 2(a)
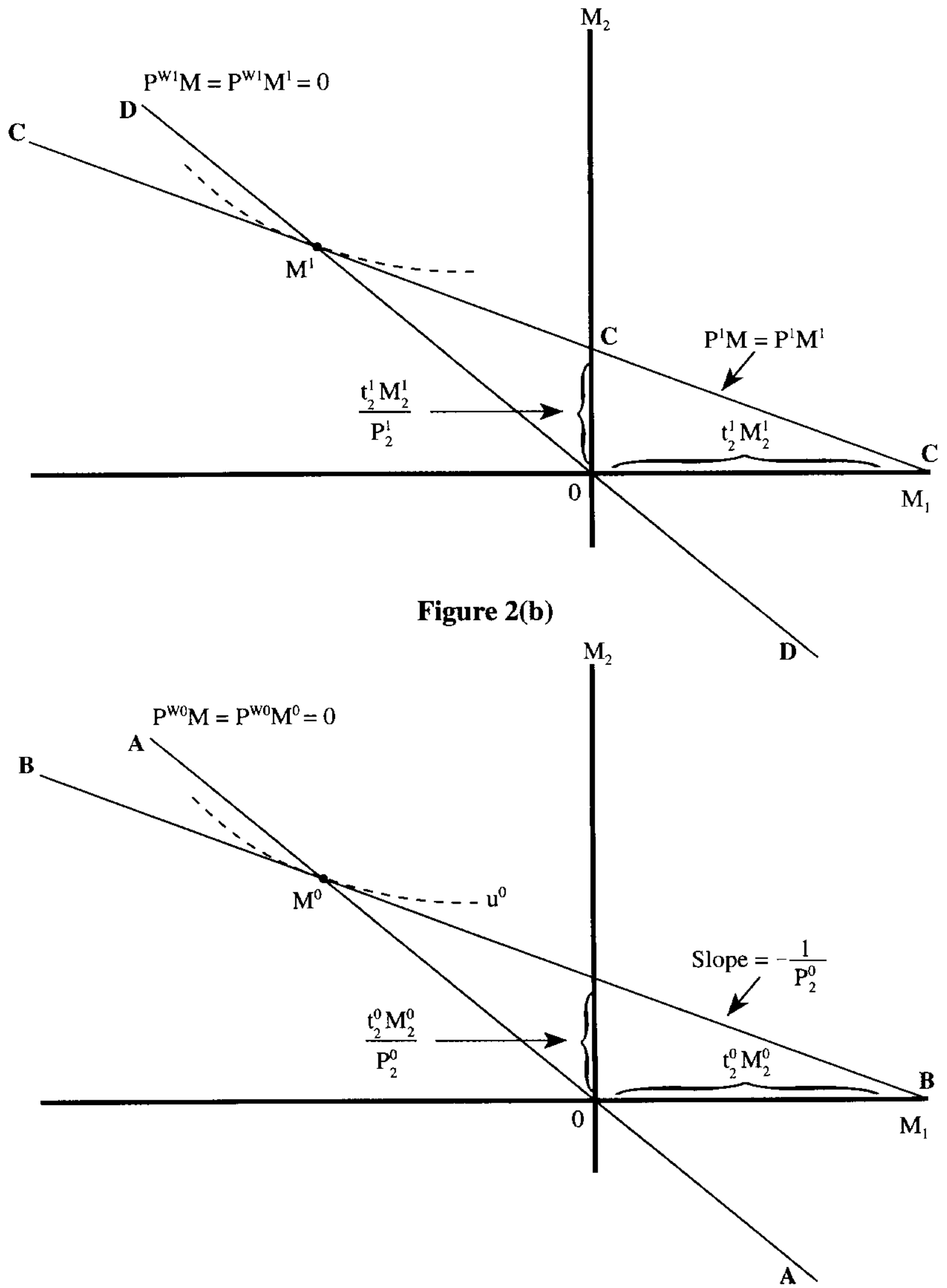